\title{
Does wheat yield depend on variety and planting time?
}

\author{
Sotvoldi Tursunov ${ }^{1, *}$ \\ ${ }^{1}$ Namangan Engineering Construction Institute, Islam Karimov str., 12, Namangan, Uzbekistan
}

\begin{abstract}
This article describes in detail the influence of sowing dates on the growth, development and productivity of various varieties of winter wheat. Wheat occupies a special place among grain crops in terms of nutritional value and yield. It is known that Uzbekistan, winter wheat is saturated with a vital factor - light. On average, 2,500-3,000 hours of sunshine per year fall on the soil of our country. Therefore, in agriculture, it is possible to determine the sowing time, which corresponds to the biological properties of winter wheat. Wheat bread is superior to other products in its deliciousness, nutritional value and ease of digestion.
\end{abstract}

\section{Introduction}

The problems of growing high yields of winter wheat in our country have been resolved, but much remains to be done to improve the technology of growing wheat $[1,9,12]$. The most important component of wheat cultivation technology is the correct determination of the optimal timing for sowing wheat seeds. Adhering to scientifically based planting dates is a key factor in obtaining a bountiful and quality crop [2, 3, 8-10]. When determining the timing of sowing, one should take into account the biological characteristics of the variety, the soil and climatic conditions of wheat soils, the level of moisture and other factors. Productivity decreases if, sooner or later, winter wheat seeds are sown $[2,4,11]$. With early sowing, wheat stalks grow too much before winter, frost resistance sharply decreases, and with late sowing, wheatgrass does not have time to accumulate until winter [4, 14-17]. In such cases, accumulation occurs in spring, the productivity of stems formed in spring is lower than that of autumn stems, and the period of grain ripening coincides with the period of high temperatures $[1,4,13]$. As a result, the grain becomes small and useless. Timely sown autumn wheat seeds germinate quickly. It completely goes through the solidification stages until the constant cold falls [1-4].

Therefore, determining the optimal timing of sowing winter wheat for each region of the country plays an important role in ensuring high yields. When determining the optimal timing of sowing winter wheat seeds, it is necessary to take into account the fact that the winter wheat plant must enter the accumulation phase and give 2-3 stems before the constant cold in this region [6-9].

It is known that in our country, winter wheat is saturated with a vital factor - light. On average, 2,500-3000 hours of sunshine per year fall on the soil of our country. Therefore,

* Corresponding author: sotvoldi.tursunov@yandex.com 
in agriculture, it is possible to determine the sowing time, which corresponds to the biological properties of winter wheat $[9,11]$.

The biological properties of winter wheat do not allow planting it too sooner or later. Finally, early-sown winter wheat under the influence of light and temperature (other varieties, except Krasnodar ones) germinate in autumn, which leads to a sharp decrease in the growth, development and yield of grain $[7,8]$.

Sown winter wheat too late sprouts slowly, does not fully emerge, does not have time to accumulate, the number of productive stems decreases, which leads to a low grain yield. As a result of many years of scientific research, we have determined the optimal time for sowing winter wheat in the southern and eastern regions of the region [5-7].

In order to obtain high yields of agricultural crops, it is necessary to apply appropriate agrotechnical measures for each variety. It is necessary to increase yields not by increasing the sown area, but by creating and using new high-yielding varieties, using advanced agrotechnical measures.

\section{Materials and methods}

In our country, there are grain varieties capable of producing a yield of 60-70 centners per hectare and even more, resistant to diseases and pests, adapted to unfavorable soil and climatic conditions. It is advisable to create a unique technology for each variety, taking into account the soil and climatic conditions of the grain-growing region $[2,4,5]$.

It is written that if one variety in one region exhibits characteristics of rapid ripening, yield, disease resistance, in another region it may be the other way around, or these characteristics may not be fully manifested. For the same reason, breeders recommend certain regions for growing widely cultivated plants. Therefore, the mapping of plant varieties introduced into the sown area is carried out [1-6].

Locally adapted varieties play an important role in the production of tall, stable and high quality crops. There are two ways to increase crop yields $[3,6]$, including winter wheat:

1. Development of new varieties with high yield potential, which can be obtained even in unfavorable environmental conditions.

2. Improvement of cultivation technology, i.e. strengthening the potential of the variety by agrotechnical measures.

Both directions are inextricably linked, because the potential of a high-yielding variety manifests itself in high agronomic conditions. In low agrotechnical conditions, the total yield of the high-yielding variety decreases slightly, while the low-yielding variety approaches.

Consequently, it remains one of the main factors in the intensification of grain production [8]. The selection of crop varieties by region is a very complex process, which is carried out by scientific institutions, highly qualified researchers in all regions of the world because productivity starts with varieties. In addition, good varieties do not yield the expected yield if not cared for properly. Many accuse the cultivar or the author of not following the appropriate agro-technological processes when caring for the cultivar $[3,7]$.

The field experiment was carried out in 4-fold repetition. The area of each variant in

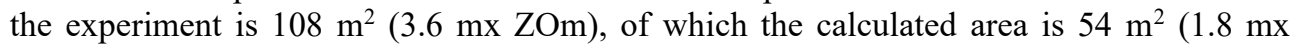
ZOm).

In the experiment, it was noticed that the winter wheat variety goes through the developmental stages. The experiment studied the periods of seed germination, accumulation, flowering and ripening. After the seedlings were fully germinated, the seedling thickness was calculated at the beginning of the spring application period and before harvest. The yield of the stems was determined before harvesting. 
Observations were carried out at all stages of development of winter wheat varieties planted in the experimental field, from germination to ripening. Productivity is determined by the number of plants per unit area and the yield of each plant. The yield of each plant and the yield of the entire crop depend on the correct number of seedlings and the method of planting. The main factors that determine the yield of grain crops are yield and plant density. Therefore, when assessing the quality of crops, it is important to determine the thickness of the plants or the number of plants per unit area.

\section{Results and discussion}

When choosing a variety, special attention should be paid to the regional character of agriculture. For example, a variety that produces good results in one condition may not yield the expected yield in another. Therefore, it is incorrect to use the template method when choosing a variety.

When determining the sowing dates, the characteristics of the varieties should be taken into account, the late varieties should be planted earlier, and the early varieties later. Winter wheat grows well for 45-55 days in the fall and requires a sum of average temperatures (above 5 degrees) of 500-550 degrees before planting before the dormant period begins.

Therefore, under irrigation conditions, it is advisable to sow winter wheat 45-60 days before the onset of cold weather, during which time the plant will enter the stage of accumulation of development and increase its winter hardiness. To carry out high-quality sowing of winter wheat, it is necessary to plan the planting correctly, to choose the right varieties. First of all, you need to choose the right varieties. First of all, late-ripening varieties with a long shelf life are planted, as early varieties are planted, such as "Intensive", "Surkhak", and "Chillaki".

From the above considerations, it can be seen that one of the ways to obtain high yields from winter wheat, and the main one is the selection of varieties that are suitable for the soil and climatic conditions of the place and give high yields. In addition, it is important to correctly determine the timing of planting each variety, taking into account the soil and climatic conditions of the regions. Therefore, we set a goal to study the timing of sowing new varieties of winter wheat in terms of yield.

It is important to identify new varieties of winter wheat, suitable for the conditions of irrigated lands in Uzbekistan, with high yields and grain quality, resistant to adverse environmental factors, and perfect development of technologies for their cultivation. The selection of intensive varieties with high yield potential plays an important role in increasing yield and grain quality. This, in turn, requires the development of cultivar cultivation technologies. To study the effect of sowing dates on the yield of different varieties of winter wheat, field experiments were carried out according to the following options (Table 1).

Table 1. Experimental system.

\begin{tabular}{|c|c|c|}
\hline$\#$ & Species & Planting time \\
\hline 1 & Kroshka & Sep 20 \\
\hline 2 & Polovchanka & Sep 20 \\
\hline 3 & Kroshka & Oct 10 \\
\hline 4 & Polovchanka & Oct 10 \\
\hline 5 & Kroshka & Oct 30 \\
\hline 6 & Polovchanka & Oct 30 \\
\hline
\end{tabular}

For the first time, the thickness of the plants is comparable to that of the grass at the germination stage. This will allow you to determine how much grass has sprouted, that is, the percentage of germinated plants in relation to the seeds that can be sown. The unstable 
growth of grasses, in turn, indicates how carefully and agronomically prepared the soil is, how well it is planted, timing, rates, etc., as well as the influence of the soil and meteorological conditions.

The resistance of crops in the experiment of winter wheat varieties to unfavorable winter conditions is practically the same. In the variants of winter wheat seeds sown on September 20 and October 10, the number of plants per $1 \mathrm{~m} 2$ was significantly higher than in the variant of wheat seeds sown on July 30.

With the timely sowing of winter wheat, the growth and development of the plant will be at the required level. In confirmation of the above considerations, the periods of seed germination in the first period of the experiment were shorter, and the development was higher than in other periods of sowing. The experiment took into account all stages of development of sowing varieties of winter wheat from germination to maturation. Influence of sowing dates on the mass yield of winter wheat varieties at the stage of development (Table 2).

Table 2. Stages of development sowing dates.

\begin{tabular}{|c|c|c|c|}
\hline \multirow{2}{*}{$\begin{array}{c}\text { Stages of } \\
\text { development }\end{array}$} & \multicolumn{3}{|c|}{ Planting time } \\
\cline { 2 - 4 } & Sep 20 & Oct 10 & Oct 10 \\
\hline Sprout & Sep 26 & Oct 16 & Nov 12 \\
\hline Accumulation & Oct 18 & Nov 4 & Nov 30 \\
\hline Wrapping & Mar 21 & Mar 23 & Mar 29 \\
\hline Spire & Apr 18 & Apr 18 & Apr 25 \\
\hline Prosperity & Apr 24 & Apr 24 & May 1 \\
\hline Ripening & June 10 & June 10 & June 18 \\
\hline
\end{tabular}

From the data in the above table, it can be seen that the Kroshka variety emerged 6 days later in the variants with sowing seeds on September 20 and October 10, and wheat seeds germinated 12 days later in the variant with sowing on October 30. This is due to a decrease in air and soil temperatures. Likewise, the wheat accumulation, tube wrapping, threshing and flowering phases were almost identical in the variants in which wheat seeds were sown on September 20 and October 10. In the variant when the sowing took place on October 30 , these stages were delayed by 6-7 days. In the experiment, wheat seeds germinated for a long time, accumulation continued in spring, the plant developed slowly, and grain ripening coincided with hot summer days. The transfer of sowing until October 30 postponed the full transition of wheat to the ripening stage by 8 days. The number of plants per unit area, their productive accumulation, and the number of grains, the number of grains and the weight of 1,000 grains are the main indicators of biological productivity (Table 3).

Table 3. Wheat yield indicators in experiments.

\begin{tabular}{|c|c|c|c|}
\hline \multirow{2}{*}{ Indicators } & \multicolumn{2}{|c|}{ Planting time } & Oct 30 \\
\cline { 2 - 4 } & Sep 20 & 512 & 378 \\
\hline \multicolumn{2}{|c|}{ Kroshka } \\
\hline $\begin{array}{c}\text { Productive stems on an } \\
\text { area of } 1 \mathrm{~m}^{2}, \mathrm{pcs}\end{array}$ & 526 & 101.2 & 87.8 \\
\hline Stem height, cm & 101.7 & 9.3 & 7.8 \\
\hline Thorn length, cm & 9.0 & 42 & 35 \\
\hline Number of grains, pcs & 39 & 42.6 & 37.1 \\
\hline Weight of 1,000 grains, gr & 40.6 & 514 & 380 \\
\hline \multicolumn{2}{|c|}{ Polovchanka } \\
\hline $\begin{array}{c}\text { Productive stems on an } \\
\text { area of } 1 \mathrm{~m}^{2}, \mathrm{pcs}\end{array}$ & 524 & 99.2 & 85.8 \\
\hline Stem height, cm & 103.7 & 9 & 7.5 \\
\hline Thorn length, cm & 9.3 & 38.9 & 31.9 \\
\hline Number of grains, pcs & 42.1 & 41.8 & 36.3 \\
\hline Weight of 1,000 grains, gr & 41.4 & & \\
\hline
\end{tabular}


From the table above, it can be seen that the number of productive stems per $1 \mathrm{~m} 2$ of area before harvesting was 524 at sowing on September 20, 512 at sowing on October 10 and 378 at sowing on October 30 . The stem heights were $103.7 \mathrm{~cm}, 101.2 \mathrm{~cm}$ and $87.8 \mathrm{~cm}$, respectively. The length of the thorn was $9 \mathrm{~cm}$ in option $1,9.3 \mathrm{~cm}$ in option 2 , and $7.8 \mathrm{~cm}$ in option 3. The number of grains in one spike was 39 in option 1. In option 2 there were 42 , and in option $3-35$. The weight of 1000 grains in the 1 st version is $40 \mathrm{~g}$. In option 2 $42.6 \mathrm{~g}$, in option $3-37.1 \mathrm{~g}$, the winter wheat variety Polovchanka has the same picture.

From the above data, it can be seen that before harvesting, the Kroshka variety was superior to the Polovchanka variety in terms of the number of productive stems per $1 \mathrm{~m}^{2}$. In terms of stem height, Polovchanka was $2.8 \mathrm{~cm}$ higher than Kroshka. In addition, the Kroshka variety showed superiority over the Polovchanka variety in the length of the ear, the amount of grain in the ear, and the mass of a thousand grains.

\section{Conclusions}

The main task of field experiments in agriculture is to scientifically substantiate the influence of the event or factor under study on plant productivity. Since productivity is the main criterion for agricultural production, the main goal of crop cultivation is to increase yields per unit area.

Factors affecting the yield of cereals: first of all, the biological characteristics of the variety, the optimal sowing time, natural and climatic conditions, the optimal sowing method, duration and rates, nutrient content and duration of use, moisture supply, disease and pest prevalence, yield, including timely collection.

In the experiment, the influence of the sowing time on the wheat yield was determined. Experimental sowing "Kroshka" on September 20 gave a yield of $64.4 \mathrm{~kg} / \mathrm{ha}$. Wheat is sown on 10 October. The yield was $66.6 \mathrm{q} / \mathrm{ha}$, wheat sown on October $30-55.8 \mathrm{~kg} / \mathrm{ha}$. The delay in sowing winter wheat seeds until October 30 reduced the yield by $9.6 \mathrm{c} / \mathrm{ha}$, it is recommended to sow seeds from September 20 to October 10.

\section{References}

1. H. Ataboeva, B. Azizov, Wheat, 78-85 (2008)

2. S. Bakhromov, Varieties of autumn wheat, created in Andijan, and their yield, 140 (2003)

3. R. Siddykov, Irrigated lands are rich in winter wheat and grain farms for growing quality grain: A guide for managers and farmers, 25-35 (2005)

4. R. Siddykov, T. Jalolov, The main factor in the intensification of emissions, 97 (2006)

5. S. Tursunov, Varieties of Planting Rates and Autumn Wheat Harvest, 113 (2006)

6. S. Turadzhonov, S. Tursunov, The yield of wheat varieties in the conditions of irrigated meadow soils of the Andijan region, 6, 14-21 (2008)

7. S. Tursunov, Grain, 45-71 (2019)

8. S. Tursunov, Botanica, 46-107 (2019)

9. S. Isaev, I. Begmatov, G. Goziev, S. Khasanov, In IOP Conference Series: Materials Science and Engineering, 883(1), 012080 (2020)

10. N. Teshaev, B. Mamadaliyev, A. Ibragimov, S. Khasanov, InterCarto. InterGIS, 26(3), 324-333 (2020) 
11. S. Isaev, S. Khasanov, Y. Ashirov, T. Karabaeva, A. Gofirov, In E3S Web of Conferences, 244, 02012 (2021)

12. R. A. Kulmatov, S. A. Adilov, S. Khasanov, In IOP Conference Series: Earth and Environmental Science, 614(1), 012149 (2020)

13. A. Jumanov, S. Khasanov, A. Tabayev, G. Goziev, U. Uzbekov, E. Malikov, In IOP Conference Series: Earth and Environmental Science, 614(1), 012150 (2020)

14. S. Isaev, S. Khasanov, Y. Ashirov, A. Gofirov, T. Karabaeva, In E3S Web of Conferences, 244, 02047 (2021)

15. M. Groll, C. Opp, I. Aslanov, Aeolian Research, 9, 49-62 (2013)

16. Z. Mamatkulov, E. Safarov, R. Oymatov, I. Abdurahmanov, M. Rajapbaev, In E3S Web of Conferences, 227, 03001 (2021)

17. N. Ch. Namozov, D. A. Kodirova, M. I. Usmonova, International journal of scientific \& technology research, 9(03), 5491-5493 (2020) 